\title{
DILUTE PHASE VERTICAL PNEUMATIC CONVEYING OF CORK STOPPERS
}

\author{
R. Barbosa ${ }^{a}$, \\ and C. Pinhob \\ ${ }^{\mathrm{a}}$ DEMGI \\ Escola Superior de Tecnologia de Viseu \\ Campus Politécnico de Repeses \\ 3504-510, Viseu, Portugal \\ rbarbosa@demgi.estv.ipv.pt \\ ${ }^{\mathrm{b}}$ CEFT-DEMEGI, FEUP \\ Universidade do Porto \\ Rua Dr. Roberto Frias, s/n Engineering \\ 4200-465 Porto, Portugal. \\ ctp@fe.up.pt \\ Corresponding author \\ ABSTRACT \\ The pneumatic conveying of cork stoppers is used in the cork processing \\ industries with equipments designed and built purely on an empirical basis. \\ Experimental studies to characterize this type of pneumatic transportation \\ have been, so far, oriented towards the study of horizontal conveying \\ processes, either for steady state transportation or for the acceleration zone. \\ However studies were carried out on the determination of the pressure drop \\ on vertical transportation of cork stoppers. Here the experimental apparatus \\ and procedure are described, and the first experimental data that have been \\ obtained are shown. In consequence a simple correlation for the pressure \\ drop in the steady state region of the conveying pipe is proposed. The \\ correlation is a function of dimensionless parameters used to characterize \\ the two phase flow under analysis. Three standard stoppers sizes and a \\ single pipe diameter were used in the experiments, all carried out at ambient \\ temperature. \\ Keywords: Vertical pneumatic conveying, pressure drop, cork stoppers.
}

\section{NOMENCLATURE}

$a \quad$ fitting parameter, Eq. (2)

$b \quad$ fitting parameter, Eq. (2)

$c \quad$ fitting parameter, Eq. (2)

$d \quad$ fitting parameter, Eq. (2)

$d_{s} \quad$ diameter of the stopper, $\mathrm{m}$

$d_{e q} \quad$ equivalent diameter of a stopper, $\mathrm{m}$

$d_{p} \quad$ particle diameter, $\mathrm{m}$

$D \quad$ pipe diameter, $\mathrm{m}$

Fr Froude number, $U_{f} / \sqrt{g D}$

$g \quad$ acceleration of gravity, $\mathrm{m} \mathrm{s}^{-2}$

$g \quad$ acceleration of gravity,

$L \quad$ pipe length, $\mathrm{m}$

$N \quad$ number of experiments

$p \quad$ pressure, $\mathrm{N} \mathrm{m}^{-2}$

Re Reynolds number, $\rho_{f} U_{f} D / \mu_{f}$

$U_{f} \quad$ intersiticial gas velocity, $\mathrm{m} \mathrm{s}^{-1}$

\section{Greek symbols}

$\theta \quad$ loading factor

$\lambda_{t} \quad$ overall friction factor

$\mu_{f} \quad$ fluid viscosity, $\mathrm{N} \mathrm{s} \mathrm{m}^{-2}$

$\rho_{f} \quad$ fluid density, $\mathrm{kg} / \mathrm{m}^{3}$

$\rho_{p} \quad$ gas density, $\mathrm{kg} / \mathrm{m}^{3}$

$\psi \quad$ sphericity of the stopper

\section{Subscripts}

$t_{c a l} \quad$ total calculated

$t_{\exp } \quad$ total experimental

\section{INTRODUCTION}

Pneumatic conveying is used in some steps of the production of cork stoppers, where particle damage through interparticle or particle and confining walls impaction has a minor effect upon the quality of the stoppers. The development of small distance transport systems for stoppers has been essentially an empirical process and only recently has been subjected of a systematic experimental approach. The research work that has been carried out so far refers only to horizontal pneumatic conveying, either in steady state (Neto and Pinho, 1998), or during acceleration conditions (Pinho, 1999; Pinho, 2001).

In the horizontal pneumatic conveying of cork stoppers, fine cork dust is released and acts as a lubricant reducing friction effects, Neto and Pinho (1998). The deposition of this fine dust is still enhanced by electrostatic generation, Smeltzer et al (1982). The conveying air pressure drop is then reduced, with the increase of the solids mass loading. This situation has already been found on solid-liquid systems; Lee et al (1974) studied polymeric solutions containing suspended fibbers and Radin et al (1975) studied the drag reduction in several dilute solidliquid suspensions. Szikszay (1988) argued that, as the measured experimental data referred to both the solids and the conveying air pressure drop, it was unreasonable to separate them. Weber (1991) also suggested that a single friction factor for the gassolid mixture should be used, instead of two separate friction factors, one for the air and the other for the solids. This question of drag reduction with the 
addition of particles into a flow stream has been recently reviewed in the book of Fan and Zhu (1998), who presented a phenomenological model to account for the drag reduction.

For vertical pneumatic conveying the important research points concern the acceleration region, the determination of correlations for the solids friction factor (Rautiainen et al, 1999) and the definition of flow choking conditions. Recent examples of studies on the characterization of the acceleration region are the publications of Dzido et al (2002) and Namkung and Cho (2002), although the works of Yang and coauthors are still a basic reference (Yang and Keairns, 1976). The mostly recommended correlations for the calculation of the friction factor are the publications of Yang, namely Yang (1973), Yang (1974) and Yang (1978). For the definition of the choking conditions, the work of Yang (1975) is again frequently recommended in many recent publications, like for example Raczek and Palica (1997) and $\mathrm{Xu}$ et al (2001). These last authors present a thorough analysis on the fundamentals of suspension collapsing in vertical conveying. However, in all these more recent publications, whatever is the subject being treated, acceleration, friction or choking conditions, the order of magnitude of the size of the particles under consideration is quite different from what is found in the pneumatic transportation of cork stoppers, hence the justification for the present study.

On the other end, although drag reduction was detected in horizontal conveying of cork stoppers, nothing was known as far as vertical conveying was concerned, and one of the main aims of this work was to find out how important this could be.

For the short distances used in pneumatic conveying of cork stoppers, the steady state transport conditions are difficultly reached and the acceleration regime becomes dominant. The theoretical determination of the acceleration length is a difficult task and the Rose and Duckworth (1961) equation is still the reference for this matter. However, it is becoming recognized that the acceleration length does not change very much with the solids loading factor and also that, such equation gives acceleration lengths below those measured for the transport of large particles, Marcus et al (1985). The present experimental measurements will allow the determination of the importance of this phenomenon in the vertical conveying, compared to what has been previously found under horizontal pneumatic conveying conditions, (Neto and Pinho 1998; Pinho, 1999; Pinho 2001).

\section{EXPERIMENTS}

The experimental system as schematically shown in Fig 1, was composed by a $6 \mathrm{~m}$ long horizontal portion where the stoppers were introduced into the conveying pipe, a vertical testing section of $6.8 \mathrm{~m}$ length and the recovery circuit composed by a small horizontal portion of $1.6 \mathrm{~m}$ and a diagonal portion $5.9 \mathrm{~m}$ long. Figure 2 presents a picture of the installation. The tube was a PVC pipe with $125 \mathrm{~mm}$ nominal diameter pipe $(121 \mathrm{~mm}$ internal diameter, $D$ ). Cork stoppers, moving in closed circuit, were introduced into the pneumatic conveying circuit through the feeding hopper, installed in the horizontal portion of the duct. This hoper was also receiving the corks after their tour into the system.

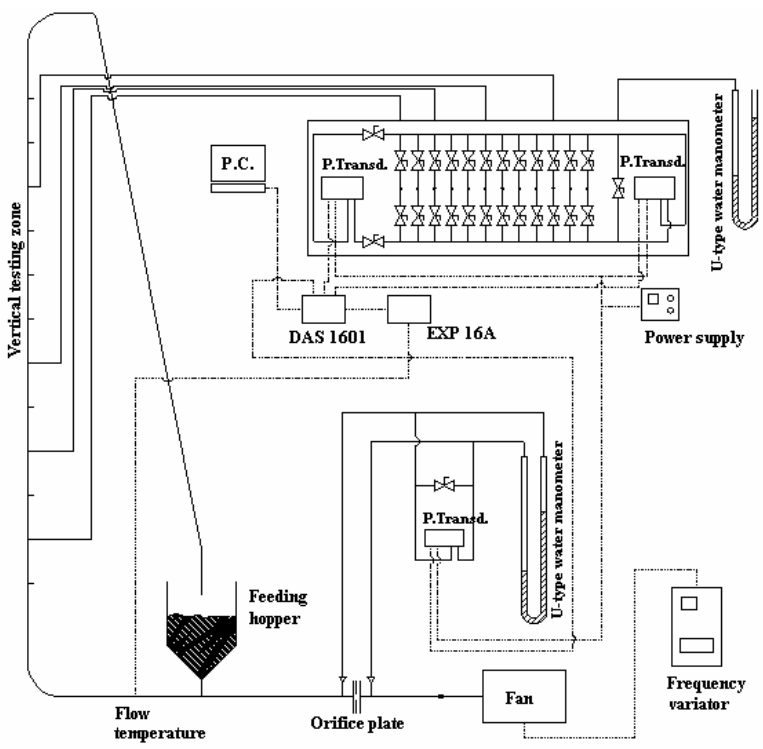

Figure 1. Schematic diagram of the experimental apparatus.

Conveying air was introduced into the system through a centrifugal fan controlled by a ABB frequency variator model ACS401000932, with a resolution of $0.1 \mathrm{~Hz} / 50 \mathrm{~Hz}$. Air flow was measured through an orifice plate flow meter, positioned upstream the feeding hopper, and equipped with a differential pressure transducer with an operating range of 0 to $1245 \mathrm{~Pa}$. The orifice plate flow meter was previously calibrated by means of a Pitot tube, installed before the feeding hopper.

To carry on with the calibration process, the conveying pipe had to be disconnected from the entrance of the feeding hopper and through the Pitot tube an average conveying air velocity was obtained with the log-linear method applied to the measurement of the air velocity in six points along the pipe diameter. To reduced the air leakage through the feeding system of the corks, the hopper connection with the conveying pipe was closely isolated with aluminium adhesive tape. With the continuous reading of conveying air temperature, corrections in the air flow rate were made for the air temperature increase with attrition effects inside the transporting pipe, as well as to account for changes in the ambient air temperature. 
Along the vertical testing section, pressure taps were fitted half a meter apart. The first pressure tap is $0.5 \mathrm{~m}$ away from the bend connecting the horizontal feeding section to the vertical testing section. For measurements of the pressure drop along the conveying pipe, differential pressure transducers in the 0 to $490 \mathrm{~Pa}$ range were used. The transducers were from Series $\mathrm{T}$ of Modus Instruments, Inc., and had output signals of $0-1 \mathrm{~V}$ dc. The transducers outputs were checked towards U-type water manometer readings. A data acquisition system (DAS 1601 plus EXP 16 boards) installed on a personal computer received information from the differential pressure transducers on use (for the orifice plate pressure drop and the conveying pressure drop), as well as temperature readings of the conveying air through a type $\mathrm{T}$ thermocouple. The accuracy of differential pressure drop measurements considering also the data acquisition process was of 9.7 $\mathrm{Pa}$ for the 0 - $1245 \mathrm{~Pa}$ pressure transducer, and of 7.9 $\mathrm{Pa}$ for the 0 - $490 \mathrm{~Pa}$ pressure transducer.

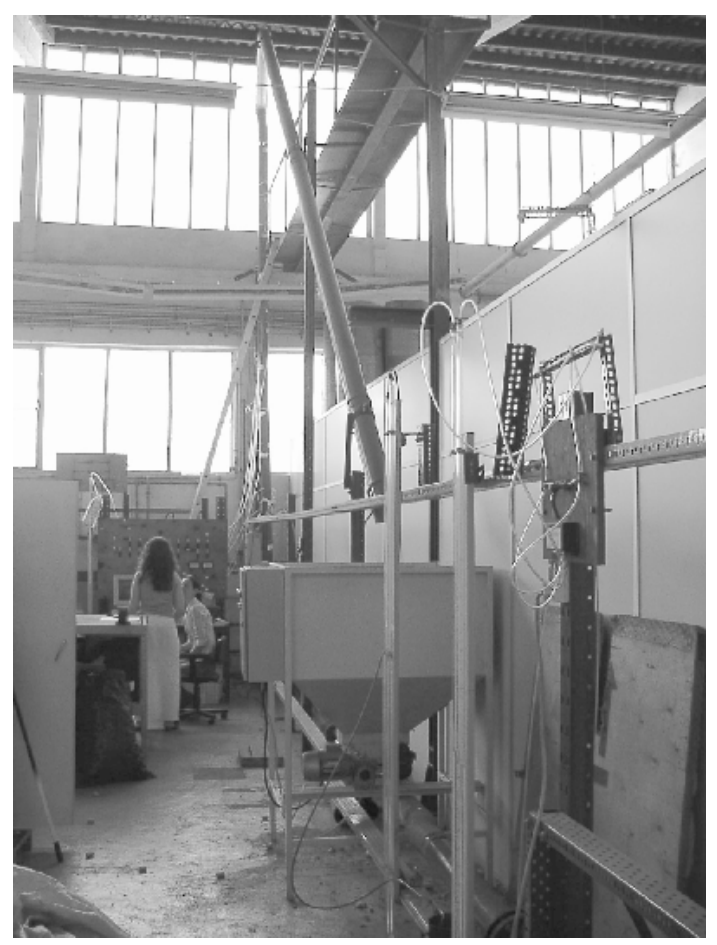

Figure 2. Experimental installation. In the first plan it can be seen the orifice plate air flow meter and the corks feeding hopper.

For each tested situation characterized by a definite air flow rate and solids loading factor $\theta$ (ratio between the solids mass flow rate and the conveying air mass flow rate), pressure drop measurements were made throughout the straight vertical transporting pipe, using all the available pressure taps. Through the adequate grouping of the pressure drop measurements, like for example the sequential combination between the first and subsequent pressure taps, it was possible to get an overall idea of the evolution of the pressure drop, as a function of particle entrance effects in the vertical portion of the pipe and also of the particle acceleration. Afterwards, by knowing the length of the steady state conveying region, pressure drop data obtained in this portion of the vertical pipe were treated in order to obtain an empirical correlation.

To calculate the mass flow rate of transported cork stoppers, a basket was used as collection device for conveyed particles. The batch of collected stoppers during a finite time interval was weighted and the solids mass flow rate could then be calculated. The measurement of the voidage fraction during pneumatic conveying was carried out through the knowledge of the amount of cork stoppers that in a given instant remain inside the pipe. Having the experimental installation working in steady state conditions, the feeding hopper was suddenly stopped and all the cork stoppers being conveyed were immediately collected and weighted. This was, for the stoppage instant, the amount of particles remaining inside the conveying system. Comparisons between the overall volume of the corks and the inside volume of conveying pipe, gave the voidage fractions under normal conveying conditions.

Table 1 presents the physical characteristics of the tested cork stoppers, size, sphericity and density.

Table 1. Characteristics of cork stoppers.

\begin{tabular}{|c|c|c|c|}
\hline $\begin{array}{c}\text { Size }\left(l \times d_{s}\right) \\
(\mathrm{mm} \times \mathrm{mm})\end{array}$ & $38 \times 22$ & $38 \times 24$ & $45 \times 24$ \\
\hline $\begin{array}{c}d_{e q} \\
(\mathrm{~m})\end{array}$ & 0.0302 & 0.0320 & 0.0339 \\
\hline$\psi$ & 0.85 & 0.85 & 0.84 \\
\hline $\begin{array}{c}\rho_{p} \\
\left(\mathrm{~kg} / \mathrm{m}^{3}\right)\end{array}$ & 167 & 155 & 139 \\
\hline
\end{tabular}

\section{RESULTS AND DISCUSSION}

The first approach towards the experiments was to analyze the importance of the acceleration region on the evolution of the pressure drop. As can be seen from Fig. 3, where some typical results are presented for the differential pressure drop between the first pressure tap and the subsequent ones, after a sudden initial rise in the pressure drop due to the entrance effects, the acceleration of the particles justifies the following strong reduction in the measured values.

Only after steady state transportation conditions are reached, the evolution of the pressure drop follows a smooth trend. This steady state situation arrives at around 3.5 to 4 meters beyond the entrance of the stoppers. This order of magnitude of the entrance/acceleration length is similar to what was found for the horizontal conveying of cork stoppers (Pinho, 1999; Pinho 2001). On the other end, 
pressure drop data obtained with pressure taps close to the end of the vertical conveying pipe were not plotted as the flow deceleration induces the increase of the pressure drop, and again unsteady conveying conditions are obtained. From this figure it is evident that, to get reliable pressure drop data for steady state pneumatic conveying, values beyond $4 \mathrm{~m}$ should be used for the determination of empirical correlations.

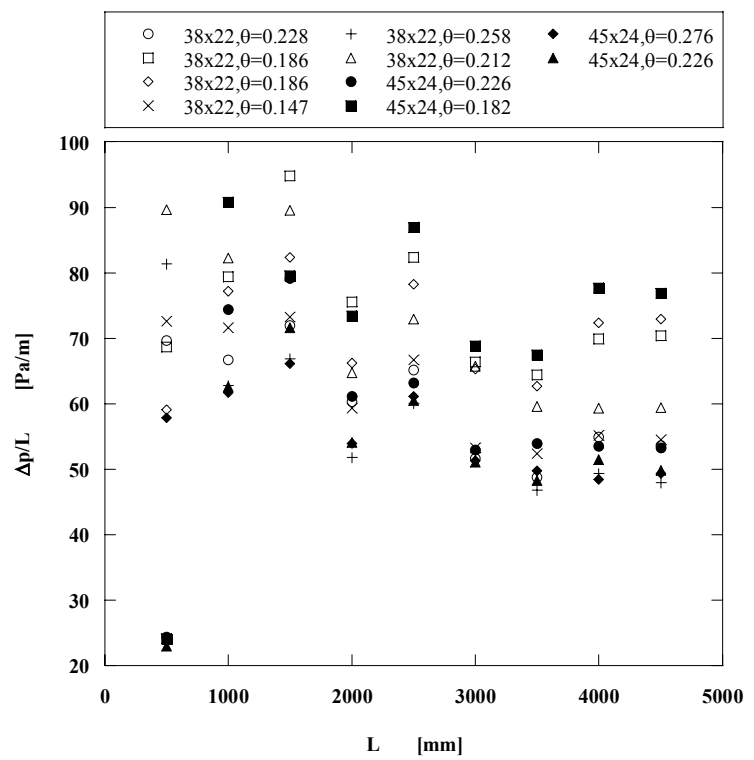

Figure 3. Evolution of overall pressure drop along the conveying pipe.

The plot of pressure drop per unit length as a function of several parameters, to characterize the operation of a pneumatic conveying system, is a typical procedure found in the technical literature (Marcus et al, 1990; Rhodes, 1998); in the situation of Fig. 3 it allows a quick definition of the acceleration region.

In classical models for pneumatic conveying, Barth (1960a; 1960b), Yang (1973; 1974; 1978) and Yang and Keairns (1973; 1976), the steady state overall pressure drop is considered to be the addition of two individual contributions, the gas and the solids pressure drop. More recently, Rhodes (1998) continues to adopt, as a general approach, the addition of individual pressure drop contributions. In these approaches, it is implicitly assumed that the overall pressure drop for a pneumatic conveying situation should be higher than any individual contribution. However, this is not always the real situation and the application of any of such models, or others following the same philosophy, would mean that some individual contributions should be negative, leading to a physically inaccurate condition. For horizontal pneumatic conveying of cork stoppers such is the situation, the overall, gas plus solid, pressure drop, is smaller than the pressure drop corresponding to the exclusive flow of air (Neto and Pinho, 1998; Pinho, 1999; Pinho, 2001). For the vertical pneumatic conveying such abnormal situation does not happen, as the experiments have shown, Fig. 4. Total, gas plus solids, pressure drop is higher than the pressure drop corresponding to the sole flow of air, as the experimental points in Fig. 4 stand, comparatively to the corresponding values obtained through the Blasius equation.

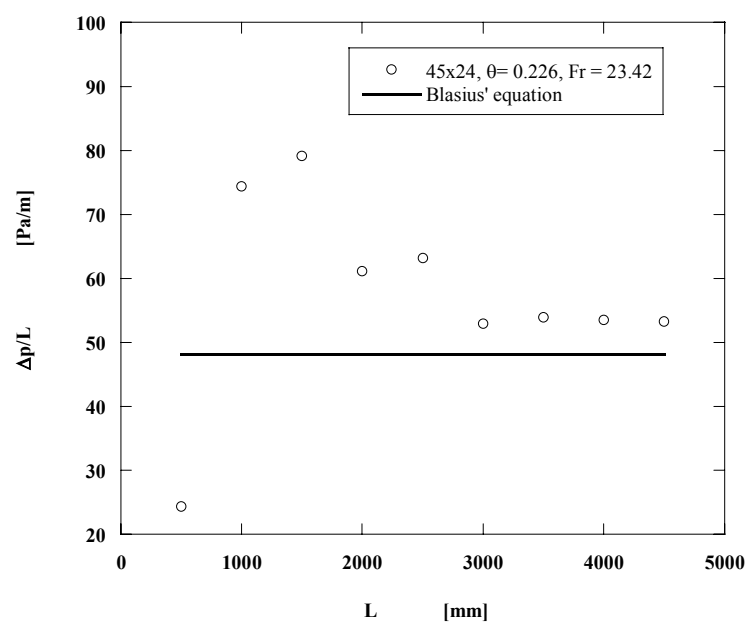

Figure 4. The overall, air plus solids, pressure drop and the corresponding values calculated through the Blasius equation.

However, as a first approach to the treatment of the experimental results, the adopted methodology was again to consider a unique overall friction factor for the gas-solid mixture, as suggested by Weber (1991). This is tempting, because the experimental determination of pneumatic conveying pressure drop is effectively the measurement of a combined (gas plus solid) pressure drop, and consequently the total pressure will then be given by,

$$
\Delta p_{t}=\lambda_{t} \frac{L}{D} \rho_{f} \frac{U_{f}^{2}}{2}
$$

where the global friction factor $\lambda_{t}$, is written as a simple function of dimensionless parameters, Szikszay (1988),

$\lambda_{t}=a \theta^{b} F^{c}\left(\frac{d_{p}}{D}\right)^{d}\left(\frac{\rho_{p}}{\rho_{f}}\right)^{e}$

Knowing experimental data of $\Delta p_{t} / L$, for different tested situations covering several stoppers diameters $d_{p}$ and densities $\rho_{p}$, loading factors $\theta$ and air interstitial velocities $U_{f}, \lambda_{t}$ is calculated by means of Eq. (1) and correlated with the dimensionless numbers referred in Eq. (2), $\theta, F r$, $d_{p} / D$ and $\rho_{p} / \rho_{f}$, through fitting parameters $a, b, c, d$ and $e$, obtained through the application of a 
commercial software for nonlinear regression analysis NLREG. The obtained values for those parameters guarantee the best fit to the set of provided experimental data obtained in the experiments.

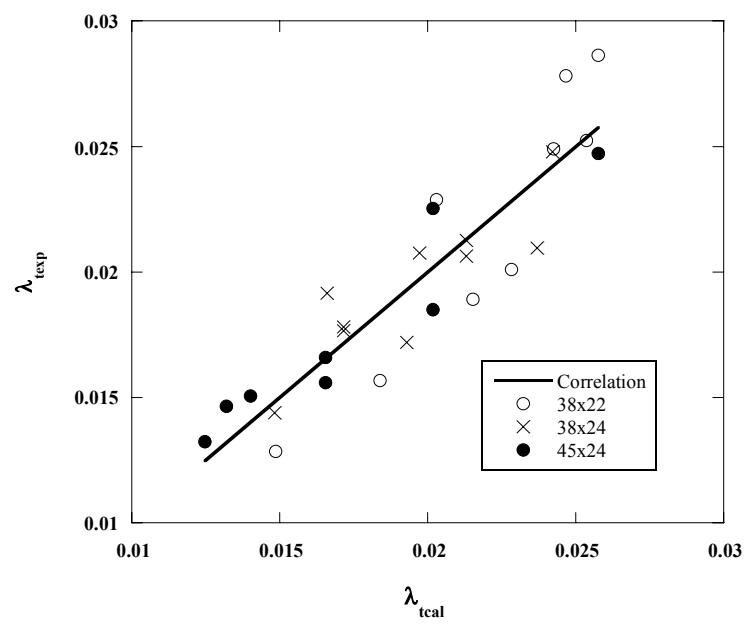

Figure 5. Comparison between experimental and calculated values for the overall friction factor.

For the determination of steady state pressure drop in horizontal pneumatic conveying, as referred in Tab. 1, three stoppers sizes were used, $38 \times 22$, $38 \times 24,45 \times 24(\mathrm{~mm} \times \mathrm{mm})$. Tested loading factors covered the range from 0.10 to 0.35 , the air flow Reynolds number $\left(R e=\rho_{f} U_{f} D / \mu_{f}\right)$ went from $1.3 \times 10^{5}$ to $2.6 \times 10^{5}$, while the Froude number $\left(F r=U_{f} / \sqrt{g D}\right)$ ranged from 15.3 to 30.7 , all values typical for cork stoppers conveying systems. In the definition of the Reynolds number, $\mu_{f}$ is the dynamic viscosity of the conveying air. Small values for the loading factor are common in the pneumatic conveying of stoppers, because of the combined influence of having to transport large size particles with the use of centrifugal fans having flat working curves promoting flow blockage situations, Wirth and Molerus (1986). This affects minimum conveying conditions and imposes restrictions on the maximum possible loading factor. At the same time, the extreme fragility of stoppers imposes some limitations on the maximum recommended transport velocity, reducing even further the range of working conditions.

The obtained correlation was then,

$$
\lambda_{t}=1.97 \times 10^{-3} \theta^{1.70} \mathrm{Fr}-0.877\left(\frac{d_{e q}}{D}\right)^{-0.830}\left(\frac{\rho_{p}}{\rho_{f}}\right)^{0.830}
$$

The maximum absolute deviation between experimental $\lambda_{\text {texp }}$ and calculated data $\lambda_{\text {tcal }}$ with this formula is of $17.4 \%$ whereas the mean deviation, calculated through

Mean Deviation $\%=\left[\sqrt{\sum\left(\frac{\lambda_{\text {tcal }}-\lambda_{\text {texp }}}{\lambda_{\text {texp }}}\right)^{2} / N}\right] \times 100$

as defined by Wen and Chen (1982), is $9.2 \%$. Experimental and calculated $\lambda_{t}$ are compared in Fig. 5.

If an alternative and more elegant correlation is adopted through the use of rounded values for the fitting parameters $a, b, c, d$ and e, the result is

$$
\lambda_{t}=2 \times 10^{-3} \theta^{1 / 5} \mathrm{Fr}^{-4 / 5}\left(\frac{d_{e q}}{D}\right)^{-4 / 5}\left(\frac{\rho_{p}}{\rho_{f}}\right)^{4 / 5}
$$

In these circumstances the absolute deviation between experimental $\lambda_{\text {texp }}$ and calculated data $\lambda_{\text {tcal }}$ with Eq. (5) is of $17.5 \%$, while the mean deviation calculated again through Eq. (4) will be 9.4 $\%$.

These data were obtained through a set of about 40 experimental runs, for each run twenty results for twelve pressure differentials were registered and each registered value corresponded to an average of a 1000 readings.

\section{CONCLUSIONS}

From the preliminary results of a study on vertical pneumatic conveying of cork stoppers, it was realized that contrary to what was found for horizontal conveying, in the vertical transportation regime the total pressure drop is higher than the pressure drop corresponding to the single flow of air.

The order of magnitude of the acceleration length is identical to that of horizontal conveying, although a deeper analysis of the experimental results is still under way.

Finally, as a preliminary approach, a simple empirical correlation for the overall (gas plus solid) pressure drop in the steady state conveying regime was proposed. By sacrificing a little of the accuracy of the original correlation, a more elegant one can be obtained through the use of rounded fitting parameters.

\section{REFERENCES}

Barth, W., 1960a, Physical and Economical Aspects of Transportation of Solids in Fluids and Gases, (In German), CIT 32, No. 2, pp.164-171. 
Barth, W., 1960b, Technical Flow Problems in Conveying Dust and Gas Mixtures, (In German), Mitt. VGB., No. 79, pp.238-244.

Dzido, G., Palica, M. and Raczek, J., 2002, Investigations of the acceleration region in the vertical pneumatic conveying, Powder Technologt, Vol. 127, pp. 99-106.

Fan, L. S., and Zhu, C., 1998, Principles of Gas-Solid Flows, Cambridge University Press, Cambridge Series in Chemical Engineering, Cambridge.

Lee, W. K., Vaseleski, R. C. and Metzner, A. B., 1974, Turbulent Drag Reduction in Polymeric Solutions Containing Suspended Fibbers, A.I.Ch.E. J., Vol. 20, No..1, pp. 128-133.

Marcus, R. D., Hilbert Jr., J. D, and Klinzing, G. E., 1985, Flow Through Bends and Acceleration Zones in Pneumatic Conveying Systems, Bulk Solids Handling, Vol. 5, No. 4, pp. 121-126.

Marcus, R. D., Leung, L. S, Klinzing, G. E. and Rizk, F., 1990, Pneumatic Conveying of Solids, Chapman and Hall, London.

Namkung, W. and Cho, M., 2002, Pressure Drop in a Vertical Pneumatic Conveying of Iron Ore, Ind. Eng. Chem. Res.,Vol. 41, pp. 5316-5320.

Neto, P. and Pinho, C., 1998, Dilute Phase Horizontal Pneumatic Conveying of Cork Stoppers: A Preliminary Experimental Study, Proceedings of the Symposium on Thermal and Fluids Engineering, CSME Forum SCGM, $19^{\text {th }}-22^{\text {nd }}$ May, Toronto, Vol. 1, pp. 360-367.

Pinho, C., 1999, Acceleration of Cork Stoppers in Pneumatic Conveying, $15^{\text {th }}$ Brazilian Congress of Mechanical Engineering, $22^{\text {nd }}-26^{\text {th }}$ November, Águas de Lindóia, São Paulo, SP, Brazil.

Pinho, C., 2001, Horizontal Pneumatic Conveying of Cork Stoppers, Proceedings of Cobem 2001, Fluid Mechanics, Vol. 8, pp 21-29, $26^{\text {th }}$ to $30^{\text {th }}$ November 2001, Uberlândia, MG, Brazil.

Raczek, J. and Palica, M., 1997, Selection of the gas working velocity in vertical pneumatic conveying systems for binary mixtures, Chemical Engineering and Processing, No. 36, pp. 167-170.

Radin, I., Zakin, J.L. and Patterson, G.K., 1975, Drag Reduction in Solid-Fluid Systems, A.I.Ch.E. J., Vol. 21, No..2, pp. 358-371.

Rautiainen, A., Stewart, G., Poikolainen, V. and Sarkomaa, P., 1999, An experimental study of vertical pneumatic conveying, Powder Technology, Vol. 104, pp 139-150.

Rhodes, M., 1998, Introduction to Particle Technology, John Wiley and Sons, Chichester.

Rose, H.E. and Duckworth, R. A., 1961, Transport of Solids Particles in Liquids and Gases, The Engineer, No. 14, $21^{\text {st }}$ and $28^{\text {th }}$ March.

Smeltzer, E. E., Weaver, M. L. and Klinzing, G. E., 1982, Pressure Drop Losses due to Electrostatic Generation in Pneumatic Transport, Ind. Eng. Chem. Process Des. Dev., Vol. 21, No. 3, pp. 390-394.
Szikszay, G., 1988, Friction Factor for Dilute Phase Pneumatic Conveying, Bulk Solids Handling, Vol. 8, No. 4, pp.395-399.

Weber, M., 1991, Friction of the Air and the Air/Solid Mixture in Pneumatic Conveying, Bulk Solids Handling, Vol. 11, No. 1, pp. 99-102.

Wen, C.Y. and Chen, L.H., 1982, Fluidized Bed Freeboard Phenomena: Entrainment and Elutriation, AIChE J., vol. 28, No. 1, pp. 117-128.

Wirth, K.-E. and Molerus, O., 1986, Solids and Gas-Solid Flows, Encyclopedia of Fluids Mechanics, Vol. 4, Ch. 15, pp. 471-484 N. P. Cheremisinoffs Editor, Gulf Publishing Company.

Xu, G., Nomura, K., Gao, S. and Kato, K, 2001, More Fundamentals of Dilute Suspension Collapse and Choking for Vertical Conveying Systems, AIChE J., Vol. 47, No. 10, pp. 2177- 2196.

Yang, W. and Keairns, D.L., 1973, Estimating the Solid Particle Velocity in Horizontal Pneumatic Conveying Lines, The Canadian Journal of Chem. Eng., Vol. 51, pp. 779-781.

Yang, W., 1973, Estimating the Solid Particle Velocity in Vertical Pneumatic Conveying Lines, Ind. Eng. Chem. Fundam., Vol. 12, No. 3, pp. 349352.

Yang, W., 1974, A Correlation for Solid Friction Factor in Vertical and Horizontal Pneumatic Conveying, AIChE J., Vol. 20, No. 3, pp. 605-607.

Yang, W., 1975, A Mathematical Definition of Choking Phenomenon and a Mathematical Model for Predicting Choking Velocity and Choking Voidage, AIChE J., Vol. 21, No. 5, pp. 1013-1015.

Yang, W. and Keairns, D.L., 1976, Estimating the Acceleration Pressure Drop and Particle Acceleration Length in Vertical and Horizontal Pneumatic Transport Lines, Pneumotransport 3. Third International Conference on the Pneumatic Transport of Solids in Pipes, $7^{\text {th }}-9^{\text {th }}$ April, pp. D7-89 - D7-98.

Yang, W., 1978, A Correlation for Solid Friction Factor in Vertical Pneumatic Conveying Lines, AIChE J., Vol. 24, No. 3, pp. 548-552.

Received: April 20, 2006
Revised: May 20, 2006
Accepted: June 20, 2006 